\title{
A Rapid, High-Throughput Iodometric Titration Method for the Determination of Active Chlorine Content of Topical Antiseptic Solutions
}

\author{
Mangum LC ${ }^{1 *}$, Garcia $\mathbf{G R}^{1}$, Niece $\mathrm{KL}^{2}$, Wenke $\mathrm{JC}^{1}$ and Akers $\mathrm{KS}^{1,3}$ \\ ${ }^{1}$ Extremity Trauma and Regenerative Medicine, US Army Institute of Surgical Research, JBSA Fort Sam Houston, Texas, USA \\ ${ }^{2}$ Axon Dx, LLC, Earlysville, Virginia, USA \\ ${ }^{3}$ Brooke Army Medical Center, JBSA Fort Sam Houston, Texas, USA
}

*Corresponding author: Lee C. Mangum, PhD, Extremity Trauma and Regenerative Medicine, US Army Institute of Surgical Research, 3698 Chambers Pass, Bldg 3611, Ft. Sam Houston, Texas, USA 78234 Tel: +210-539-9701; E-mail: lee.c.mangum.ctr@mail.mil

Received date: October 8, 2017; Accepted date: October 23, 2017; Published date: October 24, 2017

Copyright: (c) 2017 Mangum LC, et al. This is an open-access article distributed under the terms of the Creative Commons Attribution License, which permits unrestricted use, distribution, and reproduction in any medium, provided the original author and source are credited.

\begin{abstract}
Objective: A considerable number of commercially available topical antiseptic solutions rely on free available chlorine as an active ingredient due to its broad-spectrum antimicrobial activity, but limited empirical knowledge exists of the degradation kinetics of chlorine-based solutions in contact with host tissue. To better inform clinical practice, we developed and qualified a rapid and sensitive semi-automated microtiter plate-based iodometric titration assay suitable for the rapid determination of free available chlorine in small samples of dilute antiseptic solutions following contact with biological materials.
\end{abstract}

Methods: The chlorine determination method described here utilizes a novel stepwise iodometric titration approach performed entirely on a plate reader spectrophotometer equipped with a standard automatic syringe dispenser module. In this method, both titrant addition and colorimetric monitoring steps are carried out automatically, providing significantly higher sample throughput with reduced technical error when compared to the manual titration approach typically used for this type of analysis. Assay qualification was performed by measuring free available chlorine in commercial Dakin's solution at a range of concentrations during contact with human plasma in vitro and rat muscle tissue in a simulated wound model (ex vivo).

Results: The practical lower limit of quantitation for a $200 \mu \mathrm{l}$ sample using this assay was found to be approximately $0.001 \%$ mass available chlorine and agreement was excellent between measured and nominal percent mass available chlorine over the range concentrations tested. Contact with biological material was found to cause loss of reactive chlorine in Dakin's solution in seconds to minutes.

Conclusion: The semi-automated available chlorine determination method described here represents numerous improvements to traditional iodometric titration approaches by substantially decreasing required sample volume, drastically increasing throughput, and minimizing manual sample handling and error. We feel this novel method will be of value to other researchers investigating the degradation kinetics of chlorine-based solutions to improve clinical practice.

Keywords: Topical antiseptic; Chlorine activity; Automated titration; Dakin's solution; Antimicrobial agent; High-throughput microtiter plate assay

\section{Introduction}

Numerous commercially available topical antiseptic solutions rely on free available chlorine as an active ingredient, typically in the form of dilute hypochlorous acid $(\mathrm{HOCl})$ or sodium hypochlorite $(\mathrm{NaClO})$, due to its broad-spectrum antimicrobial activity. Dakin's solution (DS) is a buffered $\mathrm{NaClO}$ preparation that represents the prototypical example of this class of agents. DS was introduced more than a century ago to treat infected wounds in combat causalities during the First World War and remains available on the commercial market (Century Pharmaceuticals, Indianapolis, IN) in conjunction with newer hypochlorite and hypochlorous acid solutions. Modern $\mathrm{NaClO}$ and $\mathrm{HOCl}^{-}$based preparations are typically marketed as antiseptic skin and wound cleansers or negative pressure wound therapy instillation solutions; current examples include PhaseOne Pure Hypochlorous Solution $^{\text {TM }}$ (Integrated Healing Technologies, Franklin, TN), Vashe Wound Solution $^{\text {TM }}$ (SteadMed Medical, Fort Worth, TX), Microcyn Negative Pressure Wound Therapy Solution ${ }^{\mathrm{TM}}$ (Sonoma Pharmaceuticals, Petaluma, CA), Neutrophase Skin and Wound Cleanser $^{\mathrm{TM}}$ (Novabay Pharmaceuticals, Emeryville, CA), and Puracyn Plus $^{\text {TM }}$ (Innovacyn, Rialto, CA). Although systemic antibiotic therapy has supplanted topical antiseptics as a primary treatment modality for the management of skin and soft tissue infection, these agents remain in clinical use as adjunctive therapies for the management of chronic open wound [1-4] or in the case of DS, as a salvage therapy for Fournier's gangrene [5] and invasive fungal infections of soft tissue wounds and burns of trauma patients [6].

The antimicrobial activity of chlorine-based solutions is specifically determined by free available chlorine content, i.e. the fraction of unreacted chlorine species available to oxidize or chlorinate organic biomolecules. Hypochlorous acid is the primary active chemical species in both "pure" $\mathrm{HOCl}$ preparations and sodium hypochlorite- 
based solutions; $\mathrm{NaClO}$ readily dissociates in water to yield $\mathrm{HOCl}$ as detailed in Equation 1.

$$
\text { (Eq. 1)... } \mathrm{NaClO}+\mathrm{H}_{2} \mathrm{O} \rightleftharpoons \mathrm{HOCl}+\mathrm{NaOH}
$$

$\mathrm{HOCl}$ is a weak acid $\left(\mathrm{pK}_{\mathrm{a}}=7.53\right)$ that further dissociates to hypochlorite anion $\left(\mathrm{OCl}^{-}\right)$under alkaline conditions (Equation 2) or decomposes to $\mathrm{Cl}_{2}$ under acidic conditions in the presence of chloride (Equation 3).

$$
\begin{aligned}
& \text { (Eq. 2) } \ldots . \mathrm{HOCl} \rightleftharpoons \mathrm{H}^{+}+\mathrm{OCl}^{-} \\
& \text {(Eq. 3) } \ldots . \mathrm{HOCl}+\mathrm{Cl}^{-}+\mathrm{H}^{+} \rightleftharpoons \mathrm{Cl}_{2}+\mathrm{H}_{2} \mathrm{O}
\end{aligned}
$$

The relative proportion of each chlorine species in solution is largely $\mathrm{pH}$ dependent: $\mathrm{HOCl}$ and $\mathrm{OCl}^{-}$exist in equimolar amounts at $\mathrm{pH} 7.5$ while $\mathrm{OCl}^{-}$predominates at $\mathrm{pH}$ greater than 8 . Maximal $\mathrm{HOCl}$ levels typically exist at $\mathrm{pH} 4$ to 6 with progressively more $\mathrm{Cl}_{2}$ being formed as $\mathrm{pH}$ drops below 3.5 [7]. All reactive chlorine species exhibit powerful nonspecific bactericidal and fungicidal activity [8-11]; however, evidence suggests that $\mathrm{HOCl}$ and $\mathrm{Cl}_{2}$ possess somewhat enhanced activity compared to anionic hypochlorite due to the greater ability of uncharged species to penetrate microbial membranes $[7,12]$. Mechanistically, the dysfunction of glucose metabolism and arrest of DNA replication observed during chorine-mediated microbial killing [13-15] is primarily attributable to protein reactivity (eg. crosslinking due to sulfhydryl oxidation) $[8,16]$ and lipid membrane permeabilization via chlorination of unsaturated fatty acid substituents of membrane phospholipids $[17,18]$.

Given the highly reactive nature of free chlorine, prudent use of $\mathrm{NaClO}$ and $\mathrm{HOCl}^{-}$based antimicrobial preparations implies a balance between antimicrobial activity and human tissue toxicity [19-21]. Limited empirical knowledge exists, however, of the degradation kinetics of chlorine-based solutions in contact with host tissue. In order to better inform clinical practice, we developed a rapid and sensitive semi-automated microtiter plate-based iodometric titration assay suitable for the rapid determination of free available chlorine in small samples of dilute antiseptic solutions following contact with biological materials. Results of the application of this high-throughput method to quantify the loss of Dakin's solution activity over time due to contact with human plasma in vitro, and rodent tissue ex vivo, are also described.

\section{Materials and Methods}

\section{Materials}

Sodium hypochlorite, potassium iodide, sodium thiosulfate standard solution, and partially saponified polyvinyl alcohol (MW $31,000-50,000 ; 87-89 \%$ hydrolyzed) were purchased from SigmaAldrich (St. Louis, MO). $0.9 \%$ sodium chloride solution was obtained from Baxter Healthcare Corporation (Deerfield, IL). Synergy 2 spectrophotometer equipped with an automatic microliter-scale syringe dispenser module (P/N 7090568) was purchased from BioTek Instruments (Winooski, VT). Commercial Dakin's solution ("Full Strength"; 0.5\% $\mathrm{NaClO}$ ) was purchased from Century Pharmaceuticals (Indianapolis, IN). Human plasma was purchased from Biological Specialty Corporation (Colmar, PA).

\section{Free available chlorine assay}

A $200 \mu \mathrm{l}$ sample of dilute sodium hypochlorite solution $(0.00025 \%$ to $0.125 \%$ mass $\mathrm{NaClO}$ ) was mixed with $170 \mu$ lof a freshly prepared reaction mixture consisting of $0.5 \mathrm{ml}$ of $2 \mathrm{M} \mathrm{HCl}, 1 \mathrm{ml}$ of $0.6 \mathrm{M}$ potassium iodide, and $200 \mu \mathrm{l}$ of polyvinyl alcohol (PVA) indicator solution (5\% PVA by weight in water). Reactions were carried out at room temperature in sealed opaque black $0.5 \mathrm{ml}$ tubes in order to reduce photooxidation and chlorine loss through degassing to excessive headspace volume. Sample tubes were immediately mixed and centrifuged ( $1 \mathrm{~min}$ at $3000 \mathrm{RCF}$ ) prior to loading $100 \mu \mathrm{l}$ of sample into triplicate wells of a Corning 96-well plate. The loaded plate was placed in a Biotek Synergy 2 spectrophotometer equipped with a Biotek automatic microliter-scale syringe dispenser module and baseline absorbance was measured at $490 \mathrm{~nm}$. Sodium thiosulfate $\left(\mathrm{Na}_{2} \mathrm{~S}_{2} \mathrm{O}_{3}\right)$ titrant $(0.0001 \mathrm{M}$ to $0.1 \mathrm{M}$, depending on the starting concentration of the $\mathrm{NaClO}$ solution being titrated) was added to each well in a stepwise fashion ( $5 \mu \mathrm{l}$ per addition) using the integrated syringe dispenser module. The plate was mixed for 10 seconds following each titrant addition and absorbance was measured at 490 $\mathrm{nm}$. The spectrophotometer control software was configured to automatically repeat the titrant addition, mixing and absorbance measurement steps sequentially for a total of 20 cycles. Equivalence was determined by monitoring the decrease in $490 \mathrm{~nm}$ absorbance following each automated titrant addition step. Absorbance of reaction mix control wells (without $\mathrm{NaClO}$ or sodium thiosulfate addition) was subtracted from sample values at each measurement time point to account for autoxidation of iodide by atmospheric oxygen at low $\mathrm{pH}$. Available chlorine content of each sample, expressed as percent mass chlorine, was calculated via Equations 4 and 5 (after accounting for the dilution of the primary sample with reaction mix) using the known sodium thiosulfate titrant concentration and the volume needed to achieve equivalence, i.e., the number of titrant addition steps required for control-adjusted $490 \mathrm{~nm}$ absorbance to reach zero multiplied by the dispensation volume (Figure 1).

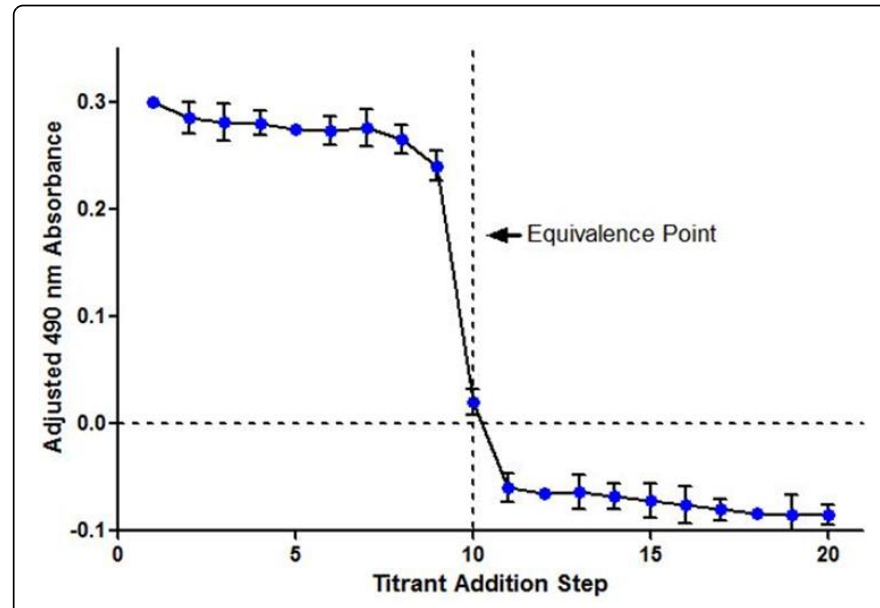

Figure 1: Representative assay titration curve illustrating equivalence determination. Data represents mean \pm SEM of $N=3$ technical replicates.

Calculated active chlorine concentration was corrected for temperature-dependent iodine extraction efficiency using the method described by Yoshinaga et al. [22].

(Eq. 4)....

Concentration $\mathrm{Cl}_{2}=$ Volume $\left(\mathrm{Na}_{2} \mathrm{~S}_{2} \mathrm{O}_{3}\right) \times$ Concentration $\left(\mathrm{Na}_{2} \mathrm{~S}_{2} \mathrm{O}_{3}\right) /$ Sample Volume $\times 2$ 
Citation: Mangum LC, Garcia GR, Niece KL, Wenke JC, Akers KS (2017) A Rapid, High-Throughput lodometric Titration Method for the Determination of Active Chlorine Content of Topical Antiseptic Solutions. J Antimicrob Agents 3: 152. doi:10.4172/2472-1212.1000152

Page 3 of 6

(Eq. 5)....

$\%$ Mass Available $\mathrm{Cl}_{2}=$ Molar Mass $\left(\mathrm{Cl}_{2}\right) \times$ Concentration $\left(\mathrm{Cl}_{2}\right) /$ Sample Specific Gravity $\times 10$

\section{Assay qualification}

To evaluate the suitability of this assay for measuring the degradation kinetics of commercially available chlorine-containing solutions, the procedure described above was used to quantify the loss of free available chlorine in Dakin's solution during contact with biological materials, both in vitro and ex vivo, under laboratory conditions. First, $30 \mathrm{ml}$ of dilute DS (nominal $0.001 \%$ to $0.0125 \%$ mass $\mathrm{NaClO}$ in $0.9 \%$ normal saline) was reacted with human plasma ( $1 \%$ or $5 \%$ by volume) for 30 minutes at room temperature in opaque black 50 $\mathrm{ml}$ polypropylene tubes. Available chlorine levels were measured throughout the incubation time course by removing serial $200 \mu \mathrm{l}$ samples of the DS/plasma mixture (beginning at 5 seconds) for processing and titration as described above. Time-matched control samples consisting of human plasma ( $1 \%$ or $5 \%$ by volume) in $0.9 \%$ normal saline were obtained and processed at each time point. Next, DS degradation during contact with skeletal muscle tissue was characterized using a rat ex vivo simulated wound model. This wound model consisted of a disarticulated hind limb of a male SpragueDawley rat, obtained under an approved tissue-sharing agreement, in which a $30 \mathrm{~mm}$ incision was created parallel with the femur to expose the gluteus maximus and biceps femoris. The incision was carried through to the level of the femoral periosteum and small tissue retractors were engaged at opposite ends of the incision to create a hollow pocket capable of holding approximately $3 \mathrm{ml}$ of solution. The wound pocket was irrigated with saline and blotted dry with sterile gauze. $2.5 \mathrm{ml}$ of DS equivalent in strength to commercial "dilute" Dakin's solution $(0.0125 \%$ mass $\mathrm{NaClO})$ was applied as a single bolus and left in place for 30 minutes. Available chlorine was serially measured throughout the time course ( 5 seconds to 30 minutes) by assaying $200 \mu \mathrm{l}$ samples of solution as above. Time-matched control samples were obtained from an identical hind limb wound model treated with $0.9 \%$ normal saline.

\section{Results}

\section{Available chlorine assay}

The practical lower limit of quantitation for a $200 \mu \mathrm{l}$ sample using this assay was found to be approximately $0.001 \%$ mass available chlorine, as determined by the ability to reliably identify the $490 \mathrm{~nm}$ absorbance shift indicating equivalence. If required, this method could be easily adapted to measure the available chlorine content of substantially smaller samples $(<50 \mu \mathrm{l})$ of more concentrated solutions (eg. $\geq 0.004 \%$ mass $\mathrm{Cl}_{2}$ ). Agreement was excellent between measured and nominal percent mass available chlorine $\left(\mathrm{r}^{2}=0.992\right)$ over a range of $0.001 \%$ to $0.125 \%$ mass sodium hypochlorite (Figure 2 ). Over this concentration range, the mean difference between measured and nominal values was less than $1 \%$ with no individual measured value more than $10 \%$ different from its respective nominal value (Figure 3 ). Accuracy and repeatability of titrant addition steps were within the limits of available instrumentation to determine differences in expected and measured weights of distilled, deionized water dispensed by the automated syringe dispenser module.

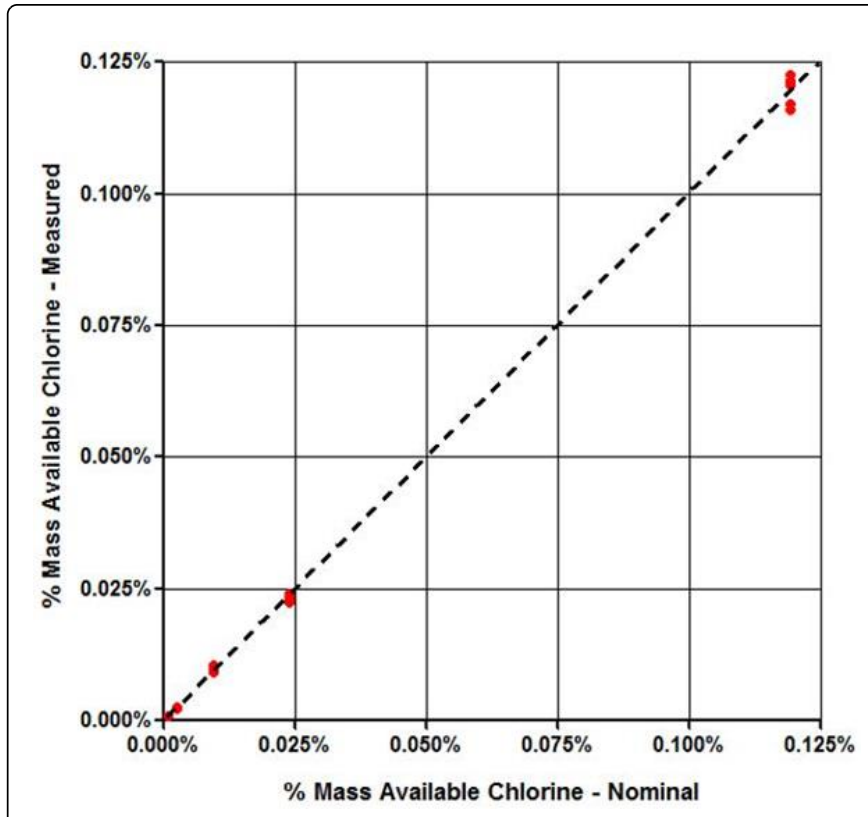

Figure 2: Measured versus nominal percent mass available chlorine value for $0.001 \%$ to $0.125 \%$ mass $\mathrm{NaClO}$ dilutions. Data represents $\mathrm{N}=5$ replicate experiments $\mathrm{R}^{2}=0.992$.

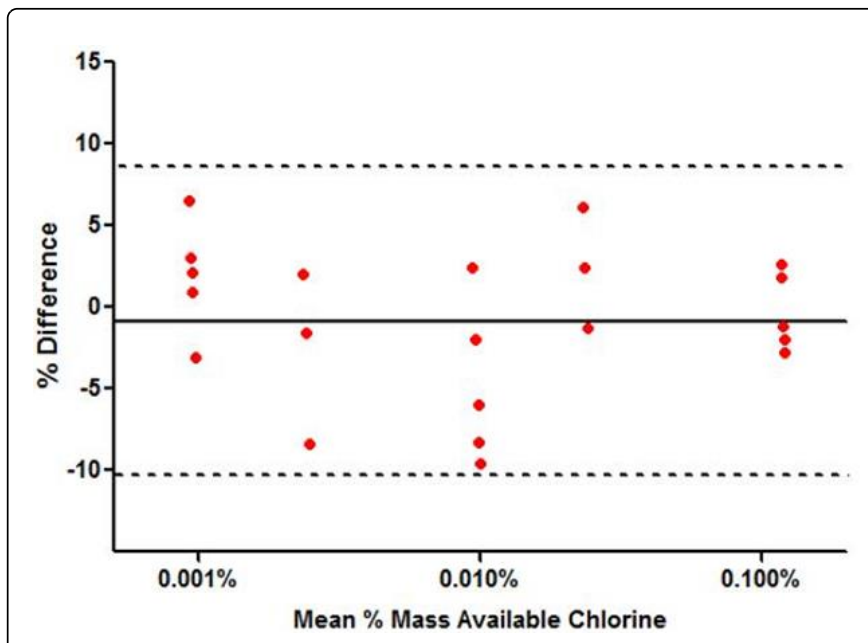

Figure 3: Bland-Altman plot of nominal versus measured percent mass available chlorine for $0.001 \%$ to $0.125 \%$ mass $\mathrm{NaClO}$ solutions. Points indicate percent difference between nominal and measured available chlorine values of individual samples versus average. Solid line indicates mean percent difference between measured and nominal values; dashed lines represent $95 \%$ limits of agreement. Data represents $\mathrm{N}=5$ replicate experiments.

\section{Assay qualification}

Contact with biological material causes extremely rapid loss of reactive chlorine in solution. In the presence of $5 \%(\mathrm{v} / \mathrm{v})$ human plasma in solution, $0.001 \%$ mass $\mathrm{NaClO}$ Dakin's solution demonstrated $61 \%$ degradation after only 5 seconds (the practical time 
Citation: Mangum LC, Garcia GR, Niece KL, Wenke JC, Akers KS (2017) A Rapid, High-Throughput lodometric Titration Method for the Determination of Active Chlorine Content of Topical Antiseptic Solutions. J Antimicrob Agents 3: 152. doi:10.4172/2472-1212.1000152

Page 4 of 6

discrimination limit of this assay) with degradation progressing to $72 \%$ by 1 minute and $85 \%$ by 30 minutes (Figures $4 \mathrm{~A}$ and $4 \mathrm{~B}$ ).

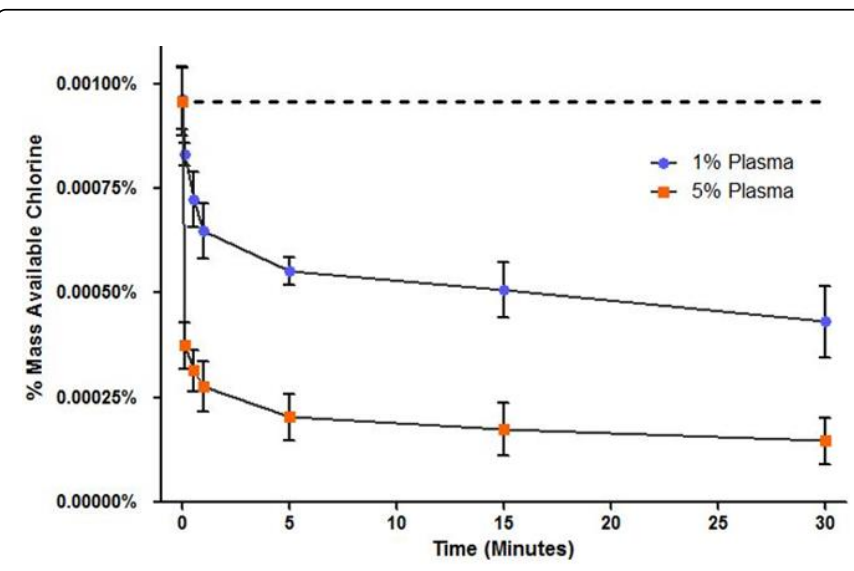

Figure 4A: Available chlorine degradation curves of Dakin's solution (DS) in contact with human plasma in vitro. $0.001 \%$ DS incubated with $1 \%$ or $5 \%(\mathrm{v} / \mathrm{v})$ human plasma for 30 minutes.

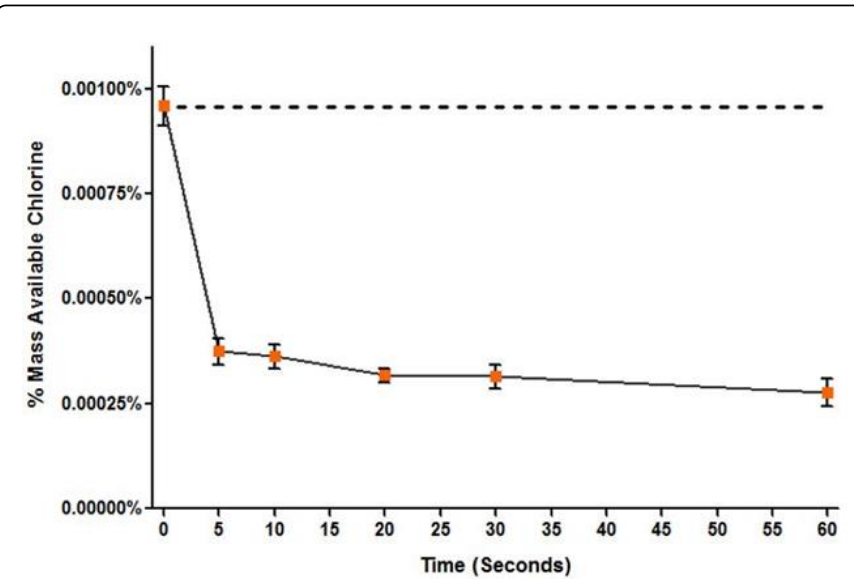

Figure 4B: Available chlorine degradation curves of Dakin's solution (DS) in contact with human plasma in vitro. 60 second kinetic profile of $0.001 \%$ DS incubated with $5 \%(\mathrm{v} / \mathrm{v})$ human plasma. Data represents mean \pm SEM of $\mathrm{N}=3$ replicate experiments; dashed line indicates measured concentration of unreacted DS prior to plasma exposure.

Total degradation was proportional to plasma concentration, with $1 \%(\mathrm{v} / \mathrm{v})$ human plasma producing $13 \%$ degradation of $0.001 \%$ DS by 5 seconds, $32 \%$ degradation at 1 minute, and $55 \%$ degradation at 30 minutes (Figure 4B). Similar degradation profiles were observed at higher DS starting concentrations, e.g. $0.0125 \%$ DS exhibited $45 \%$ degradation after 5 seconds of contact with $5 \%$ human plasma which progressed to $62 \%$ degradation at 1 minute and $75 \%$ overall loss by 30 minutes (Figure 5). Contact with soft tissue in an ex vivo wound model resulted in a slightly slower loss of free available chlorine compared to the reaction with plasma in solution: $0.0125 \%$ DS demonstrated approximately $15 \%$ degradation after 5 seconds of tissue contact, $43 \%$ degradation after 1 minute and $72 \%$ degradation by 30 minutes (Figure 6). The short centrifugation step incorporated into the sample preparation procedure was found to be sufficient to clear precipitated protein that could interfere with absorbance measurement if left in suspension.

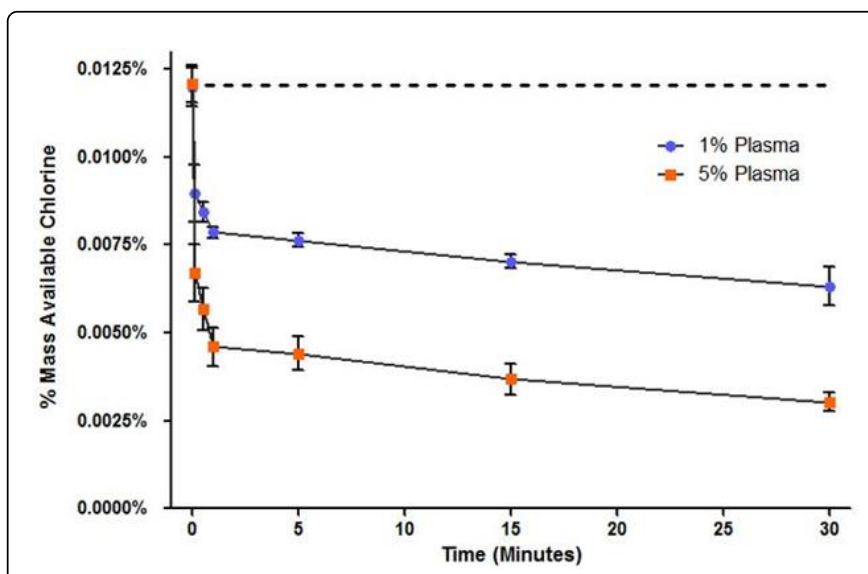

Figure 5: Available chlorine degradation curves of $0.0125 \%$ Dakin's solution (DS) incubated with $1 \%$ or $5 \%(\mathrm{v} / \mathrm{v})$ human plasma in vitro over 30 minutes. Data represents mean \pm SEM of $\mathrm{N}=3$ replicate experiments; dashed line indicates measured concentration of unreacted DS prior to plasma exposure.

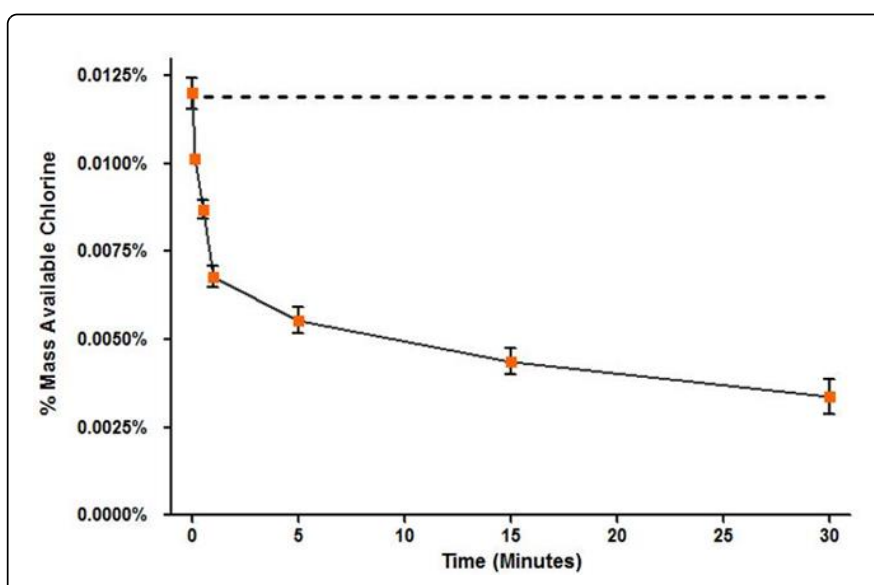

Figure 6: Reactive chlorine activity over time in $0.0125 \%$ Dakin's solution (DS) during contact with soft tissue of an ex vivo rat simulated wound model. $2.5 \mathrm{ml}$ DS instilled into wound space as a single bolus without replenishment for 30 minutes. Data represents mean \pm SEM of $\mathrm{N}=3$ replicate experiments; dashed line indicates measured chlorine concentration of unreacted DS used for treatment.

\section{Discussion}

The semi-automated method for free available chlorine determination described here represents numerous improvements to the traditional iodometric oxidation/reduction titration approach (Equation 6) intended to decrease required sample volume $(200 \mu \mathrm{l}$ compared to $2-4 \mathrm{ml}$ needed for conventional methods), drastically increase throughput, and minimize manual sample handling and error. This improved assay utilizes partially saponified polyvinyl alcohol (PVA) as a colorimetric iodine indicator (Equation 7) as previously validated by Yoshinaga et al. [23] to both substantially improve 
Page 5 of 6

sensitivity over the conventional starch indicator solution and enable one-step acidification and indicator addition suitable for automated titration. Furthermore, both the sodium thiosulfate titrant addition and colorimetric monitoring steps (Equation 8) are carried out automatically in this method, providing significantly higher sample throughput with reduced human error when compared to a typical manual titration assay. In testing, we found that 32 individual samples could be titrated in technical triplicate in approximately 27 minutes using this method.

$$
\begin{aligned}
& \text { (Eq. 6)..... } \mathrm{Cl}_{2}+2 \mathrm{KI} \rightleftharpoons \mathrm{I}_{2}+2 \mathrm{KCl} \\
& \text { (Eq. 7) } \ldots \ldots . \mathrm{I}_{2}+\mathrm{PVA} \rightleftharpoons \mathrm{I}_{2}{ }^{-} \text {PVA Complex }\left(\lambda_{\max }=490 \mathrm{~nm}\right) \\
& \text { (Eq. 8)...... } \mathrm{I}_{2}{ }^{-} \text {PVA Complex }+2 \mathrm{~S}_{2} \mathrm{O}_{3}{ }^{2-} \rightleftharpoons 2 \mathrm{I}^{-}+\mathrm{S}_{4} \mathrm{O}_{6}{ }^{2-}+\mathrm{PVA}
\end{aligned}
$$

This assay is particularly suitable for the measurement of active chlorine concentrations for in vivo studies because it is less susceptible error caused by sample contamination or discoloration (eg. hemoglobin, precipitated protein, etc.) than previous direct spectrophotometric methods [7] as it operates via the detection an abrupt colorimetric shift that is largely independent of changes in background absorbance. Other rapid, high-throughput microtiter plate-based assays have been developed for the measurement of antiseptic agents, specifically hydrogen peroxide and peracetic acid [24], but this is the first such assay for free available chlorine in which titrant addition and equivalence monitoring are carried out automatically without manual intervention.

As noted above, the summed concentrations of $\mathrm{HOCl}, \mathrm{OCl}^{-}$and dissolved $\mathrm{Cl}_{2}$ are collectively referred to in this work as percent mass available chlorine in solution. This nomenclature was specifically chosen for two distinct reasons: first, this term provides a practical means of describing the total oxidative potential of solutions of undefined $\mathrm{pH}$ or chemical composition (such as antiseptic solutions in contact with biological materials) in which the actual chlorine species profile $\left(\mathrm{eg} .\left[\mathrm{Cl}_{2}\right]\right.$ versus $[\mathrm{HOCl}]$ versus $\left.\left[\mathrm{OCl}^{-}\right]\right)$is unknown. Second, this terminology directly relates measured active chlorine content to the commercial label "strength" of sodium hypochlorite-based solutions (such as DS), which is frequently expressed as percent mass $\mathrm{NaClO}$. To clarify, the molar equivalency in oxidizing power between $\mathrm{NaClO}, \mathrm{HOCl}$, and $\mathrm{Cl}_{2}$ (Equations 1, 3 and 6), allows the nominal equivalent percent mass available chlorine for a given $\mathrm{NaClO}$ preparation to be calculated as follows:

(Eq.9)....

$\%$ Mass Available $\mathrm{Cl}_{2}=\frac{\% \text { Mass } \mathrm{NaClO}}{\mathrm{MW} \mathrm{NaClO} / \mathrm{MWCl}_{2}}=\frac{\% \text { Mass } \mathrm{NaClO}}{74.44 / 70.91}$ $=\frac{\% \text { Mass NaClO }}{1.05}$

This close approximation between percent mass active chlorine and label $\mathrm{NaClO}$ concentration allows degradation kinetics to be evaluated as a direct loss of chlorine activity from a nominal starting point. While the mass equivalency between label strength and chlorine is less direct for pure, stabilized hypochlorous acid solutions $(\mathrm{MW} \mathrm{HOCl}=$ $52.46 \mathrm{~g} / \mathrm{mol}$ ), the titration assay described here performs identically for all mixtures of $\mathrm{Cl}_{2}, \mathrm{HOCl}, \mathrm{OCl}^{-}$, and $\mathrm{NaClO}$ in commercial antiseptic solutions.

The rapid degradation profile exhibited by Dakin's solution in contact with biological materials is consistent with the high protein reactivity previously reported for hypochlorous acid [25]. In our experiments, reactive chlorine was rapidly depleted, on the order of seconds to minutes, in solutions containing even low concentrations of aqueous human plasma. Degradation was slightly slower, however, during contact with a clean tissue surface in an ex vivo simulated wound model. This different reaction profile may be attributable to the limited availability of labile biomolecules at the tissue surface in conjunction with the relatively slow rate of solubilization of unreacted molecules from the tissue into the solution phase immediately after addition of Dakin's solution. The observed rate of degradation would likely be higher in living, perfused tissue where plasma proteins would actively be infused into an exposed wound space containing DS.

\section{Conclusions}

The novel method for the determination of active chlorine described here offers multiple improvements over existing methods, and will be of value to other researchers investigating the degradation kinetics of chlorine-based solutions in contact with biological materials. This assay, and the preliminary data reported here, form a foundation for future in vivo and clinical studies focused on optimizing the dosing of chlorine-based topical antiseptics solutions to maximize antimicrobial effectiveness with minimal host tissue toxicity to improve wound healing outcomes.

\section{Disclosures}

The opinions or assertions contained herein are the private views of the authors and are not to be construed as official or as reflecting the views of the Department of the Army or the Department of Defense. The authors declare no financial or nonfinancial conflicts of interest. The authors are employees of the U.S. Government, and this work was prepared as part of their official duties.

\section{Funding}

Funding was providing by the US Army Medical Research and Materiel Command Combat Casualty Care Research Program.

\section{Acknowledgments}

This research was supported in part by an appointment to the Postgraduate Research Participation Program at the U.S. Army Institute of Surgical Research (USAISR) administered by the Oak Ridge Institute for Science and Education through an interagency agreement between the U.S. Department of Energy and USAISR.

\section{References}

1. Hiebert, Robson MC (2016) The immediate and delayed postdebridement effects on tissue bacterial wound counts of hypochlorous acid versus saline irrigation in chronic wounds. Eplasty 16: e32.

2. Felte R, Gallagher KE, Tinkoff GH, Cipolle M (2016) A case review series of christiana care health system's experience with negative pressure wound therapy instillation. Cureus 8: e865.

3. Duarte B, Cabete J, Formiga A, Neves J (2017) Dakin's solution: Is there a place for it in the 21st century? Int Wound J 2017: 12728.

4. Selkon JB, Cherry GW, Wilson JM, Hughes MA (2006) Evaluation of hypochlorous acid washes in the treatment of chronic venous leg ulcers. J Wound Care 15: 33-37.

5. Altunoluk B, Resim S, Efe E, Eren M, Benlioglu C, et al. (2012) Fournier's gangrene: Conventional dressings versus dressings with Dakin's solution. ISRN Urol 2012: 762340.

6. Lewandowski L, Purcell R, Fleming M, Gordon WT (2013) The use of dilute dakin's solution for the treatment of angioinvasive fungal infection in the combat wounded: A case series. Mil Med 178: e503-507. 
Citation: Mangum LC, Garcia GR, Niece KL, Wenke JC, Akers KS (2017) A Rapid, High-Throughput lodometric Titration Method for the Determination of Active Chlorine Content of Topical Antiseptic Solutions. J Antimicrob Agents 3: 152. doi:10.4172/2472-1212.1000152

Page 6 of 6

7. Wang L, Bassiri M, Najafi R, Najafi K, Yang J, et al. (2007) Hypochlorous acid as a potential wound care agent: Part i. Stabilized hypochlorous acid: A component of the inorganic armamentarium of innate immunity. J Burns Wounds 6: e5.

8. Estrela C, Estrela CR, Barbin EL, Spanó JCE, Marchesan MA, et al. (2002) Mechanism of action of sodium hypochlorite. Braz Dent J 13: 113-117.

9. Gray MJ, Wholey WY, Jakob U (2013) Bacterial responses to reactive chlorine species. Annu Rev Microbiol 67: 141-160.

10. Fukuzaki S (2006) Mechanisms of actions of sodium hypochlorite in cleaning and disinfection processes. Biocontrol Sci 11: 147-157.

11. Barsoumian A, Sanchez CJ, Mende K, Tully CC, Beckius ML, et al. (2013) In vitro toxicity and activity of dakin's solution, mafenide acetate, and amphotericin b on filamentous fungi and human cells. J Orthop Trauma 27: 428-436.

12. Rossi-Fedele G, Guastalli AR, Dogramaci EJ, Steier L, De Figueiredo JA (2011) Influence of $\mathrm{pH}$ changes on chlorine-containing endodontic irrigating solutions. Int Endod J 44: 792-799.

13. Rosen H, Rakita RM, Waltersdorph AM, Klebanoff SJ (1987) Myeloperoxidase-mediated damage to the succinate oxidase system of Escherichia coli. Evidence for selective inactivation of the dehydrogenase component. J Biol Chem 262: 15004-15010.

14. Albrich JM, McCarthy CA, Hurst JK (1981) Biological reactivity of hypochlorous acid: Implications for microbicidal mechanisms of leukocyte myeloperoxidase. Proc Natl Acad Sci U S A 78: 210-214.

15. Rosen H, Michel BR, VanDevanter DR, Hughes JP (1998) Differential effects of myeloperoxidase-derived oxidants on Escherichia coli DNA replication. Infect Immun 66: 2655-2659.

16. Pereira WE, Hoyano Y, Summons RE, Bacon VA, Duffield AM (1973) Chlorination studies. II. The reaction of aqueous hypochlorous acid with alpha-amino acids and dipeptides. Biochim Biophys Acta 313: 170-180.
17. Arnhold J, Panasenko OM, Schiller J, Vladimirov Yu A, Arnold K (1995) The action of hypochlorous acid on phosphatidylcholine liposomes in dependence on the content of double bonds. Stoichiometry and NMR analysis. Chem Phys Lipids 78: 55-64.

18. Pitt AR, Spickett CM (2008) Mass spectrometric analysis of hocl- and free-radical-induced damage to lipids and proteins. Biochem Soc Trans 36: 1077-1082.

19. Fleming A (1919) The action of chemical and physiological antiseptics in a septic wound. British J Surgery 7: 99-129.

20. McDonnell KJ, Sculco TP (1997) Dakin's solution revisited. Am J Orthop 26: 471-473.

21. McCullough M, Carlson GW (2014) Dakin's solution: Historical perspective and current practice. Ann Plast Surg 73: 254-256.

22. Yoshinaga T, Tsuchida M, Toyose Y, Hiratsuka H, Yamaye M (2004) Polyvinyl alcohol as a useful indicator on iodometry. (II): Temperature dependence of iodine recovery and the correction method of iodine concentration in the lower detection limit region. Anal Sci 20: 549-552.

23. Yoshinaga $T$, Shirakata $T$, Dohtsu $H$, Hiratsuka $H$, Hasegawa M, et al. (2001) Polyvinyl alcohol as a useful indicator on iodometry: Volumetric and spectrophotometric studies on iodine-pva and iodine-starch complexes. Anal Sci 17: 333-337.

24. Putt KS, Pugh RB (2013) A high-throughput microtiter plate based method for the determination of peracetic acid and hydrogen peroxide. PLoS One 8: e79218.

25. Pattison DI, Davies MJ (2001) Absolute rate constants for the reaction of hypochlorous acid with protein side chains and peptide bonds. Chem Res Toxicol 14: 1453-1464. 